\title{
Endoscopic full-thickness resection of polyps involving the appendiceal orifice: a prospective observational case study
}

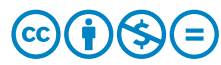

\author{
Authors \\ Maxime E.S. Bronzwaer ${ }^{1}$, Barbara A.J. Bastiaansen ${ }^{1}$, Lianne Koens ${ }^{2}$, Evelien Dekker ${ }^{1}$, Paul Fockens ${ }^{1}$
}

Institutions

1 Department of Gastroenterology \& Hepatology, Academic Medical Centre, University of Amsterdam, Amsterdam, The Netherlands

2 Department of Pathology, Academic Medical Centre, University of Amsterdam, Amsterdam, The Netherlands

submitted 26.1.2018

accepted after revision 5.3.2018

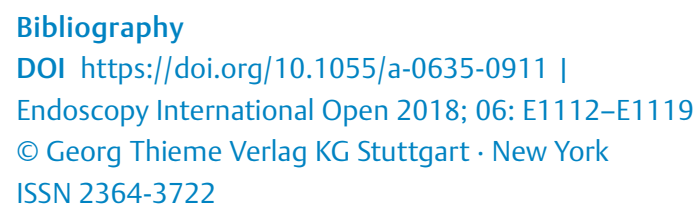

Corresponding author

Maxime Bronzwaer, MD, Department of Gastroenterology and Hepatology, Amsterdam Gastroenterology \& Metabolism, Academic Medical Center, University of Amsterdam, Meibergdreef 9, 1105 AZ Amsterdam Fax: 31206917033

m.e.bronzwaer@amc.uva.nl

\section{ABSTRACT}

Background and study aims Colorectal polyps involving the appendiceal orifice (AO) are difficult to resect with conventional polypectomy techniques and therefore often re- quire surgical intervention. These appendiceal polyps could potentially be removed with endoscopic full-thickness resection (eFTR) performed with a full-thickness resection device (FTRD). The aim of this prospective observational case study was to evaluate feasibility, technical success and safety of eFTR procedures involving the AO.

Patients and methods This study was performed between November 2016 and December 2017 in a tertiary referral center by two experienced endoscopists. All patients referred for eFTR with a polyp involving the AO that could not be resected by EMR due to more than $50 \%$ circumferential involvement of the $\mathrm{AO}$ or deep extension into the $\mathrm{AO}$ were included. The only exclusion criterion was lesion diameter $>20 \mathrm{~mm}$.

Results Seven patients underwent eFTR for a polyp involving the AO. All target lesions could be reached with the FTRD and retracted into the device. Technical success with an endoscopic radical en-bloc and full-thickness resection was achieved in all cases. Histopathological R0 resection was achieved in $85.7 \%$ of patients $(6 / 7)$. One patient who previously underwent an appendectomy developed a small abscess adjacent to the resection site, which was treated conservatively. Another patient developed secondary appendicitis followed by a laparoscopic appendectomy.

Conclusion This small exploratory study suggests that eFTR of appendiceal polyps is feasible and can offer a minimally invasive approach for radical resection of these lesions. However, more safety and long-term follow-up data are needed to evaluate this evolving technique.

\section{Introduction}

Endoscopic removal with conventional polypectomy techniques is suitable for most benign colorectal polyps [1]. However, occasionally conventional snare polypectomy cannot be performed due to increased risk of incomplete resection or perforation, for example, in cases of submucosal tumors, non-lifting polyps or polyps located at difficult anatomic locations, such as the appendiceal orifice (AO) [2-4]. To allow definitive diagnosis and treatment of these lesions, a novel endoscopic full-thickness resection device (FTRD, Ovesco Endoscopy, Tü- bingen, Germany) has been developed to perform endoscopic full-thickness resection (eFTR) with immediate secure defect closure [5-10]. Except for information from general case series describing eFTR procedures throughout the colon, little is known about detailed technical outcomes for and efficacy of eFTR procedures performed to treat polyps involving the $\mathrm{AO}$ $[5,11,12]$. Therefore, the aim of this prospective observational case study was to evaluate feasibility, technical success and safety of eFTR procedures for colonic polyps involving the AO. 

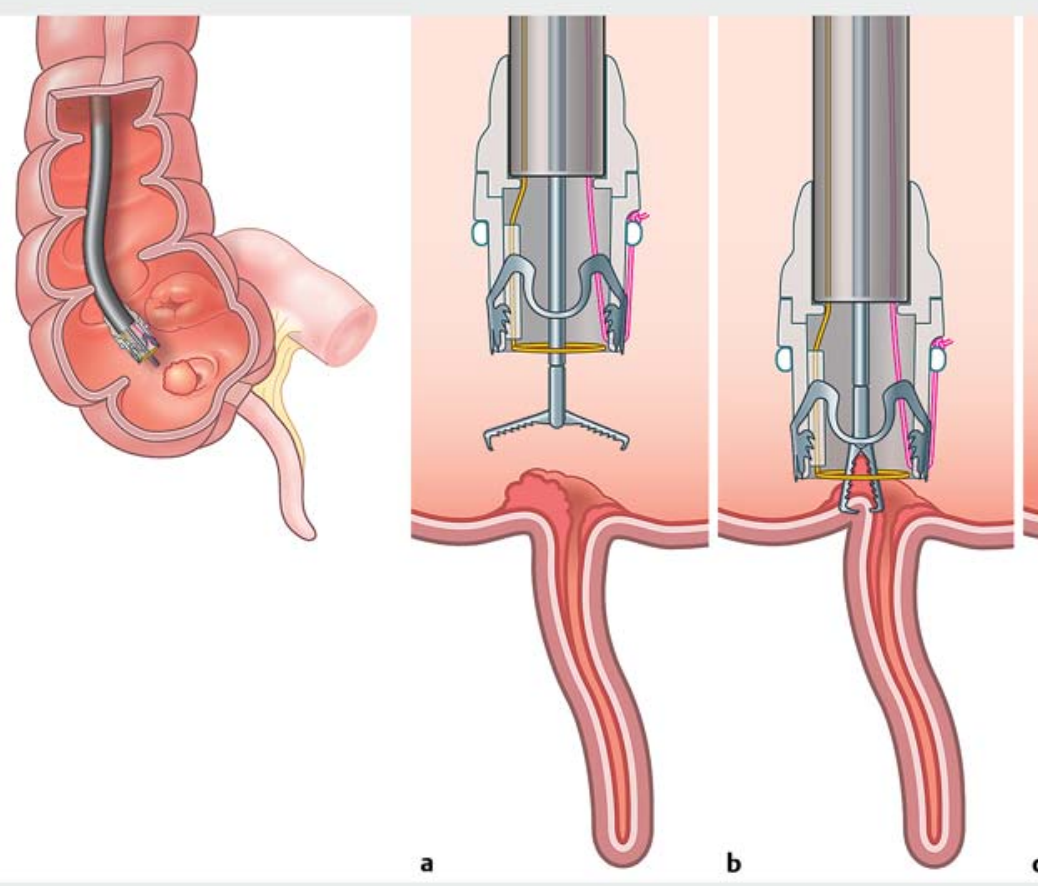
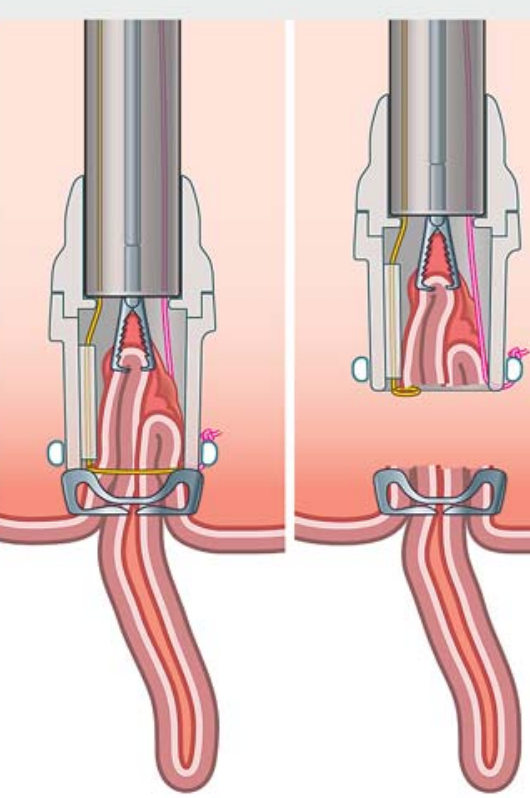

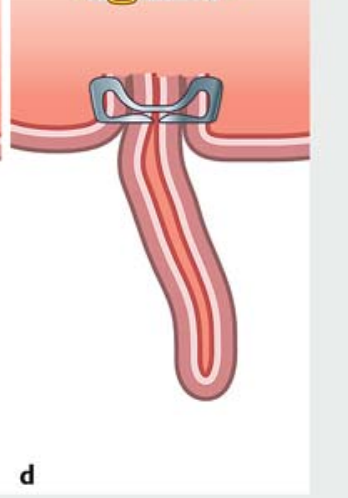

Fig. 1 Schematic illustration of the eFTR procedure of a polyp involving the AO. Source: Rogier Trompert Medical Art, www.medical-art.nl

\section{Patients and methods}

This prospective observational case study was performed in a referral center for eFTR procedures (Academic Medical Center, Amsterdam, the Netherlands). Two certified endoscopists who had extensive colonoscopy ( $\geq 1000$ procedures) and complex polypectomy experience ( $\geq 500$ procedures) performed all procedures after being trained in an ex vivo porcine model.

All patients referred for eFTR in our endoscopy center with a polyp involving the $\mathrm{AO}$ that could not be resected by endoscopic mucosal resection (EMR) due to more than $50 \%$ circumferential involvement of the $\mathrm{AO}$ or deep extension into the $\mathrm{AO}$ between November 2016 and December 2017 were included. Extension into the $\mathrm{AO}$ was defined as deep when the distal margin of the target lesion in the AO could not be overseen by the endoscopist. The only exclusion criterion applied was lesion diameter larger than $20 \mathrm{~mm}$.

\section{Description of the FTRD}

The FTRD is a pre-assembled over-the-scope device consisting of a transparent cap with a modified over-the-scope-clip (OTSC; compression width $12.3 \mathrm{~mm}$ ). The transparent cap has an inner diameter of $13 \mathrm{~mm}$ and a length of $23 \mathrm{~mm}$. A monofilament polypectomy snare is preloaded into the tip of the cap. The snare is not advanced through the working channel but runs along the outer shaft of the colonoscope underneath a plastic sheet. The device has a Conformité Européene (CE) mark and is commercially available throughout Europe [5].

\section{eFTR procedure}

All patients received standard split-dose PEG bowel preparation. All procedures were performed under propofol sedation. Prophylactic antibiotic therapy consisting of a single dose of intravenous metronidazole and cefazolin was given at the start of the procedure. Patients without a previous appendectomy received a 5-day post-procedural oral antibiotics regimen to prevent secondary appendicitis. Prior to the eFTR procedure, the target lesion was identified with a conventional colonoscope using both HD white light endoscopy (WLE) and narrow band imaging (NBI). Lesion diameter and polyp extension into the $\mathrm{AO}$ were estimated at the discretion of the endoscopist. Thereafter, the colonoscope was withdrawn and the FTRD was mounted onto the colonoscope, which was advanced to the target lesion. After identification of the target lesion, a specialized grasping forceps (Ovesco Endoscopy, Tübingen, Germany) was advanced through the working channel to grasp the lesion. The lesion was slowly pulled into the cap and with the lateral margins of the lesion pulled into the cap, the OTSC was deployed. Immediately thereafter, the pseudopolyp that was created was resected with the pre-loaded snare, while the OTSC secured the integrity of the cecal wall ( $>$ Fig. 1) [5]. The resection specimen was entrapped into the cap and withdrawn. The colonoscope without the FTRD was introduced once again to inspect the position of the OTSC.

Patients were hospitalized for 24 hours to closely monitor clinical signs of discomfort, bleeding, perforation or infection. The recommended dietary regimen was a clear fluid diet for 24 hours, and thereafter, a normal diet was started. 
- Table 1 Patient demographics.

\begin{tabular}{|l|c|}
\hline Patient characteristics & N $=7$ \\
\hline Female-no (\%) & $6(85.7 \%)$ \\
\hline Median age -years (IQR) & $64(55-67)$ \\
\hline ASA classification - no (\%) & $7(100 \%)$ \\
\hline - II: Mild systemic disease & $0(0 \%)$ \\
\hline Anticoagulant use - no (\%) & $2(28.6 \%)$ \\
\hline Appendectomy in the medical history - no (\%) & $2(28.6 \%)$ \\
\hline Primary indication of the first colonoscopy - no indications (\%) \\
\hline - FIT positive national screening program & $2(28.6 \%)$ \\
\hline - Symptoms ${ }^{1}$ & $2(28.6 \%)$ \\
\hline - Surveillance & $1(14.3 \%)$ \\
\hline - Familial history of CRC or adenoma & \\
\hline 1 Symptoms: rectal blood loss, change in bowel habits or abdominal pain \\
\hline
\end{tabular}

\section{Histopathology handling and follow-up of adverse events}

The resection specimen was stretched and pinned down on paraffin before immersion into formalin, which was analyzed by an experienced gastrointestinal pathologist. The length of the appendiceal resection was systematically assessed by measuring the length from the cecal lumen to the horizontal resection margin. Patients were contacted 14 days after the procedure to follow up on delayed adverse events.

\section{Outcome measures}

The primary outcome measure was to describe the technical success of eFTR procedures involving the AO, defined as endoscopic radical en-bloc resection of the target lesion. Secondary outcome measures included full-thickness (muscularis propria present in the resection specimen) and histopathologically proven R0 resection (vertical and horizontal margins free of polypoid tissue), occurrence of device malfunctions and procedure-related adverse events (AEs).

\section{Ethics and statistics}

The study protocol was presented to the institutional review board. Because eFTR procedures were considered part of standard health care, additional approval or informed consent was not required according to Dutch law. The study was carried out in accordance with the Declaration of Helsinki [13]. No sample size calculation was conducted for this study. For descriptive statistics, the median with interquartile range (IQR) was used for variables with a skewed distribution by using SPSS 24 (SPSS, Chicago, Illinois, United States).

\section{Results}

Between November 2016 and December 2017, eight patients were referred for eFTR of a polyp involving the AO. One patient was excluded and did not undergo eFTR because the diameter of the target lesion was $35 \mathrm{~mm}$. Three of the remaining seven

Table 2 Endoscopic target lesion characteristics.

\begin{tabular}{|c|c|c|c|c|c|c|c|}
\hline & $\begin{array}{l}\text { Preceding } \\
\text { appendect- } \\
\text { omy }\end{array}$ & $\begin{array}{l}\text { Previous- } \\
\text { ly treat- } \\
\text { ed }^{1}\end{array}$ & $\begin{array}{l}\text { Type of performed } \\
\text { treatment }\end{array}$ & $\begin{array}{l}\text { Lesion } \\
\text { diameter } \\
(\mathrm{mm})\end{array}$ & $\begin{array}{l}\text { Appendiceal } \\
\text { involvement } \\
(\%)\end{array}$ & $\begin{array}{l}\text { Paris Classifi- } \\
\text { cation }\end{array}$ & $\begin{array}{l}\text { Macroscopic } \\
\text { aspect } \\
\text { (KUDO) }\end{array}$ \\
\hline 1 & No & No & & 10 & $50 \%$ & Is & Serrated \\
\hline 2 & Yes & Yes & Diagnostic biopsies & 20 & $100 \%$ & Ila & Serrated \\
\hline 3 & No & Yes & $\begin{array}{l}\text { Successful lifting } \\
\text { Incomplete poly- } \\
\text { pectomy attempt }\end{array}$ & 12 & $75 \%$ & Ila & Adenomatous (III-V) \\
\hline 4 & No & Yes & Successful lifting & 5 & $50 \%$ & Is & Serrated \\
\hline 5 & Yes & Yes & Diagnostic biopsies & 12 & $75 \%$ & Is & Serrated \\
\hline 6 & Yes & Yes & $\begin{array}{l}\text { Successful lifting } \\
\text { Incomplete poly- } \\
\text { pectomy attempt }\end{array}$ & 10 & $100 \%$ & Is & Adenomatous (III-V) \\
\hline 7 & No & Yes & $\begin{array}{l}\text { Endoscopic lifting, } \\
\text { non-lifting sign }\end{array}$ & 15 & $50 \%$ & Is & Serrated \\
\hline Overall & $\begin{array}{l}3 / 7 \\
(42.9 \%)\end{array}$ & $\begin{array}{l}6 / 7 \\
(85.7 \%)\end{array}$ & & $\begin{array}{l}12 \\
(10-15)^{2}\end{array}$ & $\begin{array}{l}75 \% \\
(50-100)^{2}\end{array}$ & $\begin{array}{l}\text { Is } \\
5 / 7(71.4 \%) \\
\text { Ila } \\
2 / 7(28.6 \%)\end{array}$ & $\begin{array}{l}\text { Adenomatous } \\
2 / 7(28.6 \%) \\
\text { Serrated } \\
5 / 7(71.4 \%)\end{array}$ \\
\hline
\end{tabular}



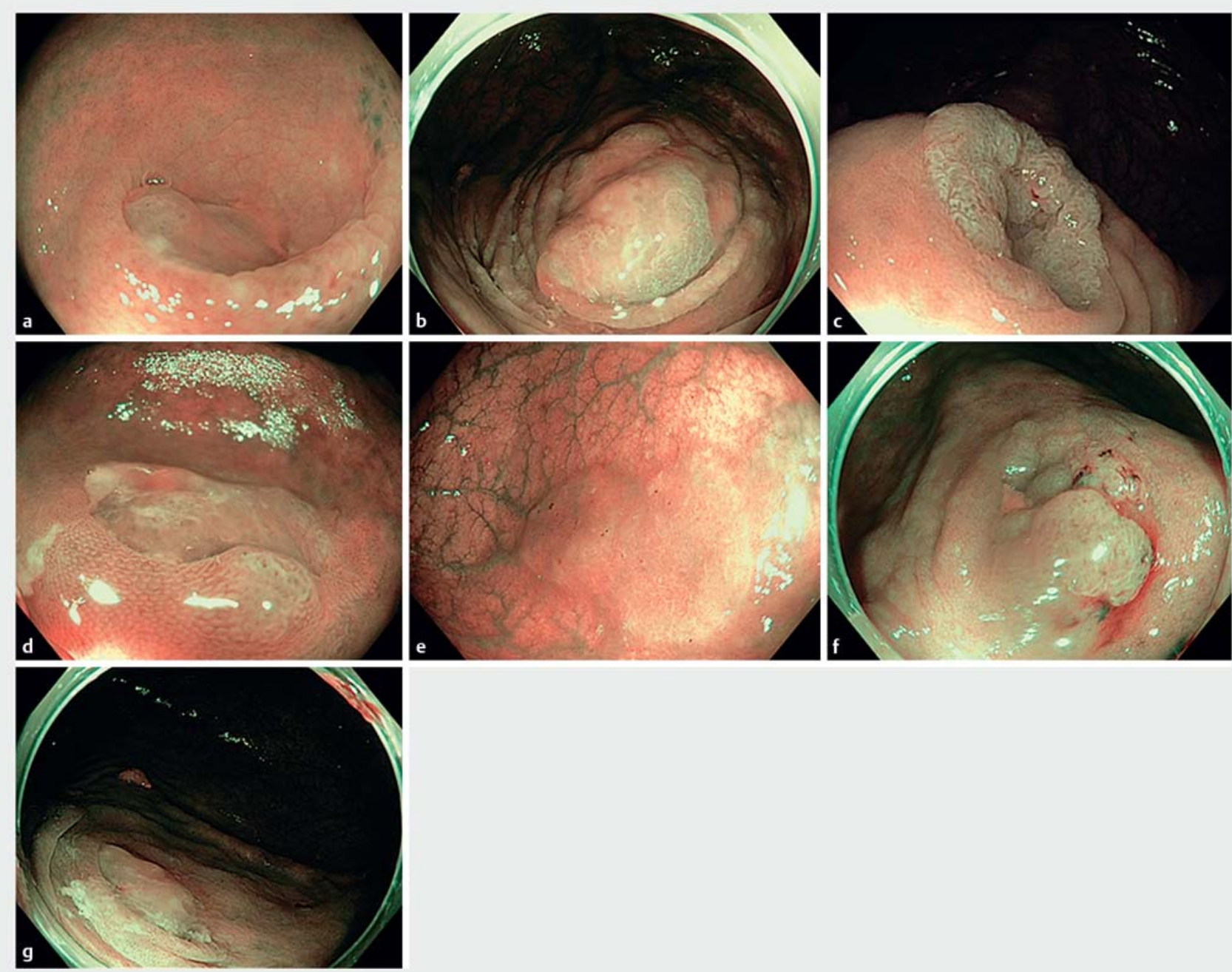

- Fig. 2 Endoscopic images of colorectal polyps involving the AO prior to eFTR.

patients had previously undergone appendectomy. Other patient demographics are shown in $>$ Table1.

\section{Polyp characteristics}

All lesion characteristics are shown in $>$ Table 2 . Six of seven polyps were previously biopsied or treated by a lifting and/or snare polypectomy attempt. Median polyp size estimated at the endoscopist's discretion during colonoscopy was $12 \mathrm{~mm}$ $(10-15)$, all polyps were non-pedunculated and during endoscopy, five appeared as sessile serrated lesions ( $\mathbf{F i g . 2}$ ).

\section{eFTR characteristics, histopathology and adverse events}

All lesions could be reached and retracted into the FTRD and all procedures resulted in an endoscopic radical en-bloc resection ( $>$ Table 3, > Fig. 3, > Fig.4, > Fig.5). No device malfunctions and immediate AEs or discomfort occurred. All resections were full-thickness with histopathological radical vertical resection margins, as shown in > Table 3 and > Fig.6. The horizontal margin of the third case was positive for serrated tissue, result- ing in a R0 resection rate of $85.7 \%$ (6/7). Surveillance colonoscopy performed 6 months later showed a clear and histopathologically proven recurrence ( $\triangleright$ Fig. 7 ). Subsequently, this patient underwent laparoscopic cecectomy.

Two patients developed fever and abdominal discomfort in the lower right quadrant of the abdomen 2 days after eFTR. Abdominal computed tomography (CT) scan of one patient revealed a small abscess adjacent to the OTSC after a preceding appendectomy (sixth case) and the CT scan of the other patient (seventh case) showed secondary appendicitis. The abscess was treated with ultrasound-guided puncture and aspiration of the abscess content and the patient with the secondary appendicitis subsequently underwent laparoscopic appendectomy. Both procedures were followed by intravenous and oral antibiotic regimens for 7 days. 
- Table 3 Procedural and histopathological characteristics.

\begin{tabular}{|c|c|}
\hline Procedural characteristics & $N=7$ \\
\hline Target lesion reached - no (\%) & $7(100 \%)$ \\
\hline Target lesion retracted into the FTRD - no (\%) & $7(100 \%)$ \\
\hline $\begin{array}{l}\text { Endoscopic macroscopic en-bloc resection - } \\
\text { no }(\%)\end{array}$ & $7(100 \%)$ \\
\hline Device malfunction - no (\%) & $0(0 \%)$ \\
\hline $\begin{array}{l}\text { Median total duration of the procedure includ- } \\
\text { ing colonoscopy without FTRD - minutes (IQR) }\end{array}$ & $38(33-57)$ \\
\hline $\begin{array}{l}\text { Median total duration of the eFTR procedure - } \\
\text { minutes (IQR) }\end{array}$ & $20(19-37)$ \\
\hline Intra procedural complications - no (\%) & $0(0 \%)$ \\
\hline Post procedural complications - no (\%) & $2(28.6 \%)$ \\
\hline - Secondary appendicitis & $1(14.3 \%)$ \\
\hline - Appendicular abscess & $1(14.3 \%)$ \\
\hline Post-procedural admission - no (\%) & $7(100 \%)$ \\
\hline - Median duration of admission - days (IQR) & $1(1-1)$ \\
\hline $\begin{array}{l}\text { Prophylactic antibiotic treatment given per } \\
\text { procedura - no (\%) }\end{array}$ & $7(100 \%)$ \\
\hline $\begin{array}{l}\text { Post procedural antibiotic treatment given - } \\
\text { no (\%) }\end{array}$ & $5(71.4 \%)$ \\
\hline \multicolumn{2}{|l|}{ Histology - no (\%) } \\
\hline - Sessile serrated lesion & $6(85.7 \%)$ \\
\hline - Tubular adenoma & $1(14.3 \%)$ \\
\hline \multicolumn{2}{|l|}{ Dysplasia - no (\%) } \\
\hline - Low-grade dysplasia & $2(28.6 \%)$ \\
\hline - Negative for dysplasia & $5(71.4 \%)$ \\
\hline R0 resection - no (\%) & $6(85.7 \%)$ \\
\hline - Vertical margins free of polyp & $7(100 \%)$ \\
\hline - Horizontal margins free of polyp & $6(85.7 \%)$ \\
\hline Full thickness resection - no (\%) & $7(100 \%)$ \\
\hline $\begin{array}{l}\text { Median size of total resection preparation - } \\
\mathrm{mm}(\mathrm{IQR})\end{array}$ & $34(29-35)$ \\
\hline $\begin{array}{l}\text { Mean/median size of total resection prepara- } \\
\text { tion-mm (IQR) }\end{array}$ & $15(7-17)$ \\
\hline $\begin{array}{l}\text { Median length from the cecal lumen to the } \\
\text { horizontal resection margin - } \mathrm{mm}(\mathrm{IQR})\end{array}$ & $8.25(8.00-9.25)$ \\
\hline $\begin{array}{l}\text { FTRD, full-thickness resection device; eFTR, endosco } \\
\text { section; IQR, interquartile range }\end{array}$ & ull-thickness re- \\
\hline
\end{tabular}

\section{Discussion}

This small, prospective, observational case study showed that the relatively new eFTR technique to resect polyps involving the $\mathrm{AO}$ was feasible with good technical success. All lesions could be reached and retracted, although advancing the colo-

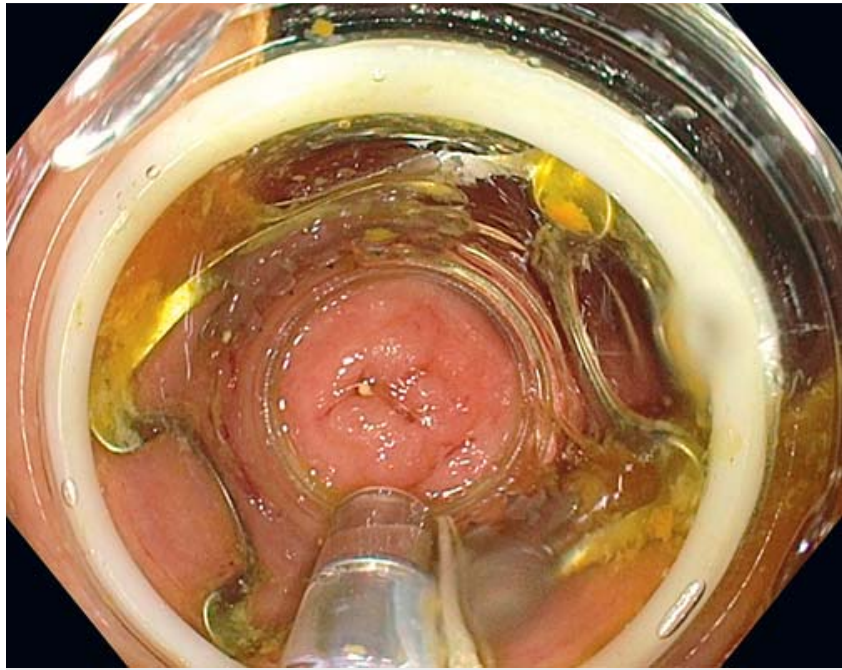

Fig. 3 Endoscopic image of the OTSC mounted onto the colonoscope.

noscope with the mounted FTRD to the AO can be challenging due to the length of the device, especially through angulated or fixated diverticular segments. Furthermore, all procedures resulted in endoscopic radical en bloc and histopathologically proven full-thickness resections.

In our study, the horizontal margin was positive in one case, resulting in an $\mathrm{R} 0$ resection rate of $85.7 \%$. Median resection length of the appendix was $8.25 \mathrm{~mm}$ (IQR $8.00-9.25)$. It is important to understand that the appendix is only partially resected during eFTR, due to partial inversion of the appendix into the cecum before OTSC placement and subsequent resection ( $\vee$ Fig. 1). As a result, radical resection of target lesions that extend deeper into the $\mathrm{AO}$ is possible, especially because during colonoscopy, it is difficult to oversee the exact depth of extension into the appendix. Therefore, in cases with positive horizontal resection margins, it is important to perform follow-up colonoscopy to evaluate for recurrent polypoid tissue, and if it is present, additional surgical resection may be warranted.

Because the lateral margins of the target lesion are easier to overlook endoscopically with eFTR than the deep horizontal margin in the $\mathrm{AO}$, radical resection of the lateral margin is probably less likely. In this small study, lateral margins were all negative. However, if radical resection did occur, follow-up endoscopy would be indicated. If macroscopic recurrence is present either endoscopic resection attempts with conventional resection techniques or additional surgery could be treatment options, depending on the size and location of the recurrence. Although in the majority of patients the OTSC will spontaneously be detached from the cecal wall, it is possible for the OTSC to still be in position. If so, a bipolar cutting device (remOVE System, Ovesco Endoscopy) is available from the manufacturer to remove the OTSC [12].

Although all patients received prophylactic antibiotic treatment, one patient developed secondary appendicitis. This was most likely caused by retained mucus within the remaining appendix, which was occluded by the OTSC. Furthermore, another 

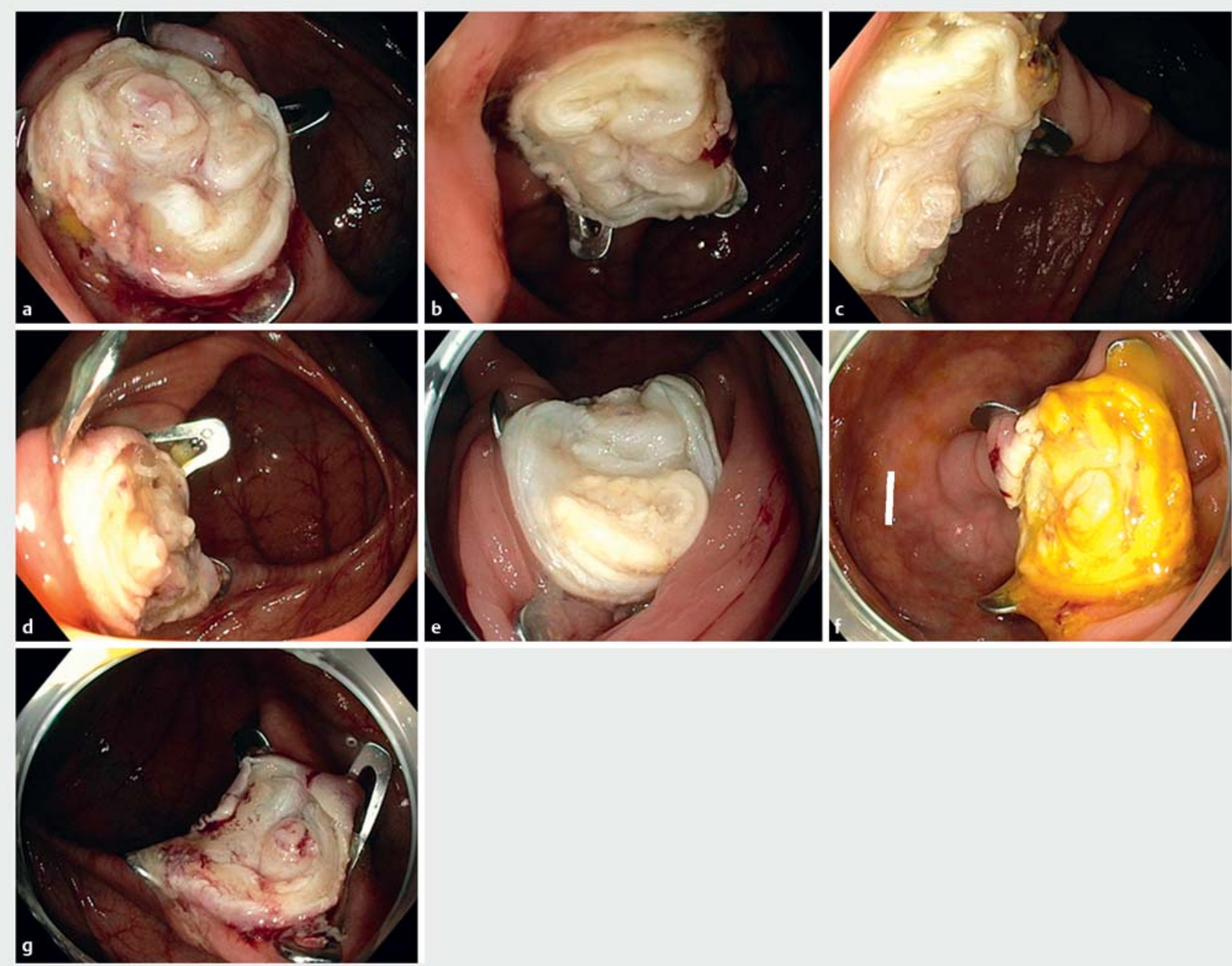

- Fig. 4 Endoscopic images after eFTR.

patient developed a small abscess adjacent to the OTSC, which was treatable conservatively. In a recent prospective multicenter study, three of 34 (8.8\%) patients undergoing eFTR for a polyp involving the $\mathrm{AO}$ developed secondary appendicitis and one patient required additional laparoscopic appendectomy [12]. This risk seems lower when compared with the findings from our study, however, caution is required in comparing results in these limited number of cases.

Endoscopic resection of polyps involving the $\mathrm{AO}$ is often regarded as controversial due to a high risk for incomplete resection and perforation. For this reason, patients are commonly referred for surgical resection. Recently successful endoscopic resection of polyps involving the AO with EMR or ESD has been described in expert tertiary endoscopy centers. However, these procedures mainly involved lesions without deep extension into the $\mathrm{AO}$ or when less than $50 \%$ of the circumference of the AO was involved [14-17]. For lesions with a diameter less than 20 mm combined with a more than $50 \%$ circumferential involvement of the $\mathrm{AO}$ or deep extension into the AO, eFTR could be an important alternative endoscopic strategy. This is especially true considering that eFTR is less demanding to perform and relatively easy to learn $[11,12]$.

\section{Conclusion}

In conclusion, eFTR of AO polyps is feasible and appears to be effective in this small prospective case study performed in a single tertiary referral center. However, before eFTR of appendiceal polyps can routinely be applied as a minimally invasive and cost-effective alternative to surgical resection, further larger multicenter studies involving safety and long-term followup data are warranted.

\section{Acknowledgements}

- Fig. 1 was created by Rogier Trompert Medical Art, Maastricht, The Netherlands 

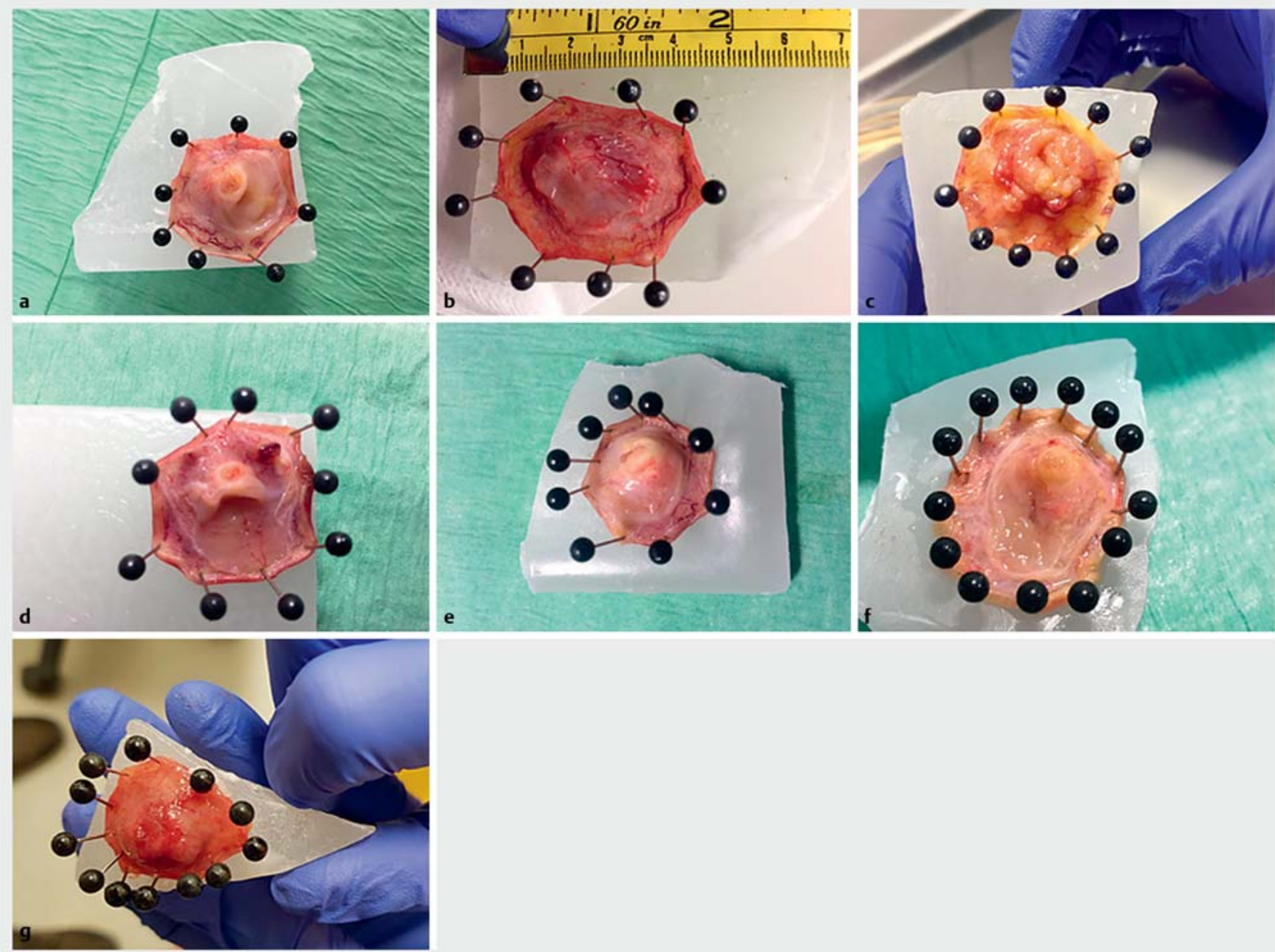

Fig. 5 Macroscopic images of resection specimens after eFTR.
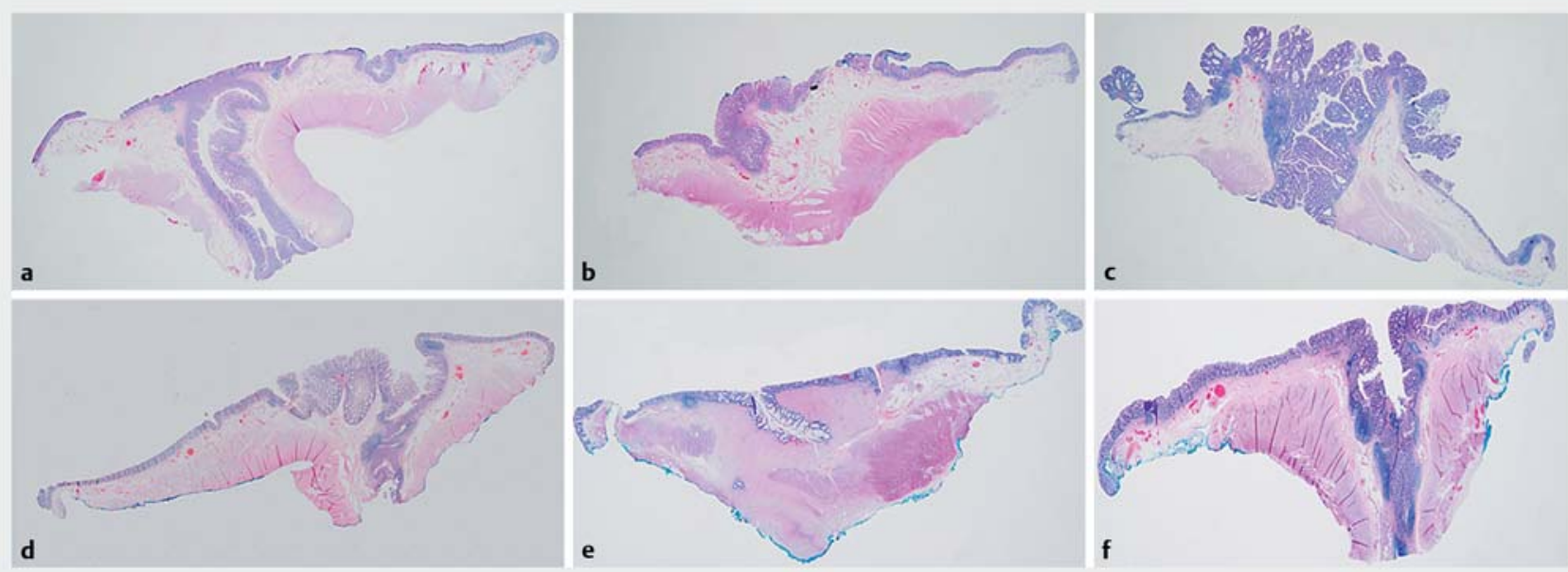

Fig. 6 Microscopic histopathologic images of resection specimens after eFTR. 


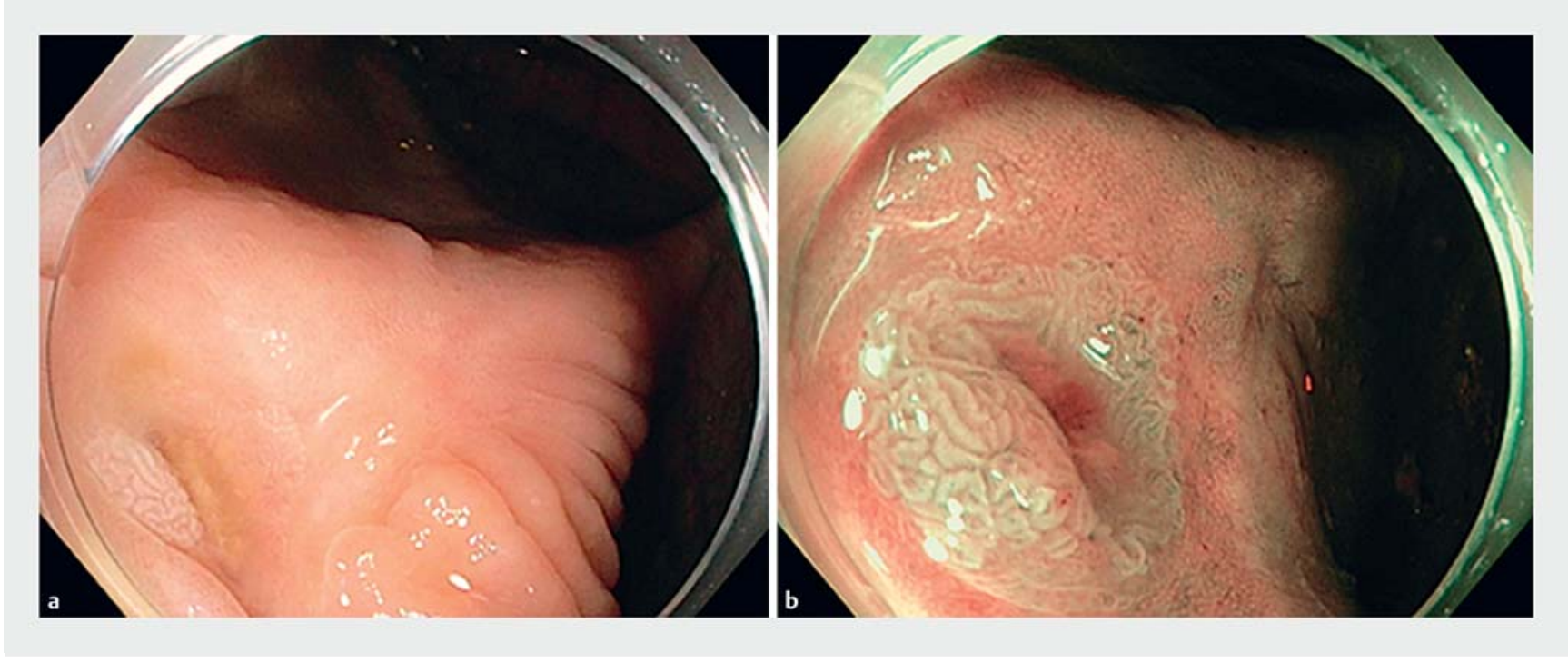

- Fig. 7 Endoscopic visible recurrence 6 months after eFTR of a sessile serrated lesion with low-grade dysplasia in the third case.

\section{Competing interests}

Dr. Dekker received endoscopic equipment on loan from Fujifilm and Olympus and received research grants from Fujifilm and Olympus, outside the submitted work. Dr. Fockens reports personal fees from Cook, Ethicon Endosurgery, Fujifilm, Medtronic and Olympus outside the submitted work.

\section{References}

[1] Ferlitsch M, Moss A, Hassan C et al. Colorectal polypectomy and endoscopic mucosal resection (EMR): European Society of Gastrointestinal Endoscopy (ESGE) Clinical Guideline. Endoscopy 2017; 49: $270-297$

[2] Rutter MD, Chattree A, Barbour JA et al. British Society of Gastroenterology/Association of Coloproctologists of Great Britain and Ireland guidelines for the management of large non-pedunculated colorectal polyps. Gut 2015; 64: $1847-1873$

[3] Kuroki Y, Hoteya S, Mitani T et al. Endoscopic submucosal dissection for residual/locally recurrent lesions after endoscopic therapy for colorectal tumors. J Gastroenterol Hepatol 2010; 25: 1747-1753

[4] Sakamoto T, Saito Y, Matsuda T et al. Treatment strategy for recurrent or residual colorectal tumors after endoscopic resection. Surg Endosc 2011; 25: 255-260

[5] Schmidt A, Bauerfeind P, Gubler C et al. Endoscopic full-thickness resection in the colorectum with a novel over-the-scope device: first experience. Endoscopy 2015; 47: 719-725

[6] Schurr MO, Baur F, Ho CN et al. Endoluminal full-thickness resection of Gl lesions: a new device and technique. Minim Invasive Ther Allied Technol 2011; 20: 189-192
[7] Schurr MO, Baur FE, Krautwald M et al. Endoscopic full-thickness resection and clip defect closure in the colon with the new FTRD system: experimental study. Surg Endosc 2015; 29: 2434-2441

[8] von Renteln D, Kratt T, Rosch T et al. Endoscopic full-thickness resection in the colon by using a clip-and-cut technique: an animal study. Gastrointest Endosc 2011; 74: 1108-1114

[9] von Renteln D, Rosch T, Kratt T et al. Endoscopic full-thickness resection of submucosal gastric tumors. Dig Dis Sci 2012; 57: 1298-1303

[10] Schmidt A, Damm M, Caca K. Endoscopic full-thickness resection using a novel over-the-scope device. Gastroenterology 2014; 147 : $740-742 . e 2$

[11] Valli PV, Mertens ], Bauerfeind P. Safe and successful resection of difficult Gl lesions using a novel single-step full-thickness resection device $\left(\right.$ FTRD $\left.^{\circledR}\right)$. Surg Endosc 2018; 32: 289- 299

[12] Schmidt A, Beyna T, Schumacher B et al. Colonoscopic full-thickness resection using an over-the-scope device: a prospective multicentre study in various indications. Gut 2018; 67: $1280-1289$

[13] World Medical A. World Medical Association Declaration of Helsinki: ethical principles for medical research involving human subjects. JAMA 2013; 310: $2191-2194$

[14] Song EM, Yang HJ, Lee HJ et al. Endoscopic Resection of Cecal Polyps Involving the Appendiceal Orifice: A KASID Multicenter Study. Dig Dis Sci 2017; 62: $3138-3148$

[15] Binmoeller KF, Hamerski CM, Shah JN et al. Underwater EMR of adenomas of the appendiceal orifice (with video). Gastrointest Endosc 2016; 83: 638-642

[16] Jacob H, Toyonaga T, Ohara Y et al. Endoscopic submucosal dissection of cecal lesions in proximity to the appendiceal orifice. Endoscopy 2016; 48: 829-836

[17] Tate DJ, Desomer L, Awadie H et al. Endoscopic mucosal resection of laterally spreading lesions around or involving the appendiceal orifice: technique, risk factors for failure, and outcomes of a tertiary referral cohort (with video). Gastrointest Endosc 2018; 87: 1279-1288.e2 